\title{
THE BOUNDED OPPORTUNITIES OF DIGITAL ENTERPRISES IN GLOBAL ECONOMIC PERIPHERIES
}

\author{
DR. NICOLAS FRIEDERICI ${ }^{+*}$ \\ Tel. +44 (0)1865 616996 \\ email: nicolas.friederici@oii.ox.ac.uk
}

\author{
PROF. MARK GRAHAM ${ }^{+}$
}

Tel. +44 (0)1865 287203

email: mark.graham@oii.ox.ac.uk

\author{
+ Oxford Internet Institute, University of Oxford \\ 1 St Giles, Oxford, OX1 3JS, UK \\ * corresponding author
}

Acknowledgments: This work has received financial support under the European Union's Seventh Framework Programme (FP/2007-2013) / ERC Grant Agreement n. 335716. Participants of the Development Implications of Digital Economies (DIODE) workshop in October 2017 in Oxford provided invaluable feedback on an earlier version. We also thank the anonymous reviewers who provided feedback on earlier drafts. 


\title{
THE BOUNDED OPPORTUNITIES OF DIGITAL ENTERPRISES IN GLOBAL ECONOMIC PERIPHERIES
}

\begin{abstract}
Digital enterprises from the US, Europe, and East Asia have been recognized for their potential to achieve global market reach, and for forming a globalized digital infrastructure. However, digital enterprises from economically peripheral countries have usually remained local. This paper seeks to understand the enterprise-level reasons for these global differences. Drawing on in-depth interviews with founders, we empirically examine the value creation and geographical market scope of 73 digital enterprises in Lagos, Nairobi, Accra, and Kigali. We develop theory that explains why enterprises in global economic peripheries are able to exploit some but not all opportunities of digital technologies. In contrast to the claim in current scholarship that digital enterprises can operate in relatively unbounded ways, we find that African enterprises cannot compete in global digital markets and are ultimately compelled to offer localized digital products. Based on these findings, we theorize that digital products with the greatest global scaling potential are the least likely to be owned and controlled by digital enterprises located in economic peripheries. We thus encourage scholars of digital enterprise to more carefully take geographical variation into account, and acknowledge technological drivers of increasing unevenness in the global digital economy.
\end{abstract}

Keywords: digital entrepreneurship, digital infrastructure, economic opportunity, digital economy, globalization, Africa, peripheries 


\section{INTRODUCTION}

The worldwide spread of Internet connectivity has sparked hopes for new entrepreneurial opportunities to arise at unprecedented levels. Digital technologies have recently been praised as "revolutionary," "open," "inclusive," "shared," "democratizing," and "levelling" forces for entrepreneurship and innovation (Aldrich 2014; Ndemo and Weiss 2017; Sussan and Acs 2017; Tilson, Lyytinen, and Sørensen 2010), given their potential to untether enterprises from their home contexts and structural boundaries (Amit and Zott 2001; Nambisan 2017). Autio et al. $(2018,80)$ summarize that

digitalization has the general effect of reducing the dependency of new ventures on clusterspecific spatial affordances for entrepreneurial opportunities, while also alleviating some of the spatial constraints of opportunity pursuit and enabling new ventures to experiment with and discover business models that exploit opportunities external to the cluster.

This article examines whether such claims about "unbounded" and "level" economic opportunity for digital entrepreneurship apply to the world's economic peripheries. We thereby seek to explore a marked tension that has recently arisen in the literature. Economic geography has long established that digital technologies do little to bring about a "death of distance" or an “end of geography” (Leamer and Storper 2001; Zook 2000, 2001; Malecki 2002; Kolko 2000). Similarly, economic geographers studying regional advantages have found that the global spatial division of labor and the clustering of production activities is in fact more pronounced for digital technologies than for many other sectors (Saxenian 1994; Bresnahan, Gambardella, and Saxenian 2001; Zook 2005, 2002; Malecki and Moriset 2007). These more nuanced studies forcefully rejected and replaced overblown and simplistic visions from the early days of the Internet: that it would end the need for cities, let businesses be footloose, and render agglomerations of production a thing of the past (Cairncross 1997; Friedman 2005).

However, more recently, the ascendance of firms like Google, Facebook, Uber, Oracle, or SAP, which operate close to global scale, has inspired a new wave of theorizing among strategy and information systems scholars, suggesting that the Internet is becoming an enabler 
of new and potentially vast entrepreneurial opportunity (Nambisan 2017). While these authors steer clear of broader death-of-distance arguments at the regional or cluster level, they point to a newfound ability for digital enterprises to scale quickly and widely, using the distancebridging potential of the Internet and the generative potential of digital innovations (Tilson, Lyytinen, and Sørensen 2010; Nambisan 2017; Henfridsson and Bygstad 2013). Specifically, this literature suggests two drivers of a potential geographical levelling of entrepreneurial opportunities: digital enterprises' ability to use and build on a globalizing digital infrastructure independently of their location (Aldrich 2014; Tilson, Lyytinen, and Sørensen 2010; Greengard 2010; Nambisan 2017), and their potential ability to reach distant and international markets (Amit and Zott 2001; Autio et al. 2018; Nambisan 2017).

To examine if these arguments are applicable to enterprises outside of centers of digital technology production in North America, Europe, and parts of Asia, we choose Africa as our empirical scope, since it is the continent that is most peripheral within the global digital economy (Carmody 2013; Murphy, Carmody, and Surborg 2014; Ojanperä et al. 2017). African digital enterprise thus represents an opportunity to study how actors in peripheries are able to induce local economic development (or not) following the expansion of an intricately interconnected global digital economy (Malecki and Moriset 2007). We collected and analyzed data on 73 digital enterprises in four African cities (Lagos, Kigali, Accra, and Nairobi) in 2017.

Our findings show that African digital enterprises are almost always users of global digital infrastructures, but this rarely helps them access distant markets. Ironically, African enterprises appeared to find the most viable growth opportunities not by scaling at distance but by localizing digital products. As African digital entrepreneurs recognize and pursue opportunities through a contextually specific lens (Alvarez, Barney, and Anderson 2012), they become further and further enmeshed in the analog realities of their local geographies. Digital tools and global platforms undoubtedly allow some enterprises to pursue distant opportunities. 
Yet, such distant markets tend to either be piecemeal or dominated by better-resourced enterprises based elsewhere in the world. These findings lead us to argue that, the more digital (and thus layered and scalable) products are, the less likely they are to be created and controlled by digital enterprises founded in peripheries.

As ever more businesses and policymakers in Africa and other economic peripheries look for ways to establish local digital sectors, this paper offers nuanced and grounded insights about persistent boundaries to the geographical scope of digital enterprises. By pointing to stubborn barriers that remain for peripheries, we point to location-based limitations that require consideration for enterprise strategies and policies to be effective. While the findings from this paper may be sobering, they offer a more realistic path forward compared to hopes that a digital revolution may simply melt geographical boundaries away for every enterprise, everywhere.

\section{LITERATURE REVIEW}

Digital entrepreneurship refers to entrepreneurship that is enabled or deeply impacted by digital technologies (Nambisan 2017), including the Internet, mobile applications, social media, cloud computing, and artificial intelligence. Entrepreneurship, or the entrepreneurial process, is defined here as any market and opportunity-oriented micro-level behavior that leads to novel initiatives, especially the startup of new and independent ventures (Alvarez, Barney, and Anderson 2012; Davidsson 2005). Outcomes of this process are digital product innovations, defined as "products or services that are either embodied in information and communication technologies or enabled by them" (Lyytinen, Yoo, and Boland Jr. 2016, 49).

Digital enterprises create value by exploiting digital affordances, like the reprogrammability and homogenization of data, which in turn enable separation of form and function and unprecedented combinatorial potential (Nambisan 2017; Yoo et al. 2012; Yoo, Henfridsson, and Lyytinen 2010). These properties are rooted in the editability, interactivity, openness, and distributedness of digital artefacts (Kallinikos, Aaltonen, and Marton 2010). In 
the remainder of this section, we highlight three features identified in the literature as distinctive of digital enterprises (Amit and Zott 2001; Nambisan 2017): their reliance on a globalized digital infrastructure, particular modes of value creation, and addressing markets at distance.

\section{The Rise of a Globalized Digital Infrastructure}

Digital product innovations exploit a layered modular design architecture, where digital components of one product can be re-used and recombined within another (Yoo, Henfridsson, and Lyytinen 2010). The layered architecture of digital technologies (Benkler 2006) interacts with the modular architecture of physical technology, including the hardware (computers, fiber-optic cables, etc.) that is necessary as a physical conduit for digital artefacts (Yoo, Henfridsson, and Lyytinen 2010).

The result is a spectrum of products from more layered to more modular, where software (consisting of digital artefacts that run on computer hardware) falls on the layered end, analog industrially manufactured products fall on the modular end, and digitized products (e.g., smart electric grids) lie somewhere in between (Yoo, Henfridsson, and Lyytinen 2010). The possibilities of combinatorial innovation are greatest at the software end, as new digital products can be combined from previous components, and stacked on top of previous layers, at low cost and by distributed actors (Benkler 2006; Gao and Iyer 2006; Yoo et al. 2012).

Ultimately, this stacking of layers upon layers has brought about a "generative" process of digital innovation that has created a rich digital infrastructure (Tilson, Lyytinen, and Sørensen 2010; Zittrain 2009), consisting of interoperable digital tools, platforms, and standards. Increasing digitization, a convergence between telecommunications and computer industries, and the global diffusion of the Internet have helped this digital infrastructure extend into most industries in most countries on earth (Malecki and Moriset 2007; Yoo et al. 2012). Its key technological components (i.e., software, telecommunications and wireless technology, 
hardware) are developed in specialized production centers in the US, Europe, and South and East Asia (Malecki and Moriset 2007; Steinbock 2003).

Digital infrastructure represents an external enabler of entrepreneurial opportunity (Nambisan 2017). The worldwide spread of the Internet has inspired optimism that this enabling function could level digital economic opportunity on a global scale. While Nambisan (2017) notes distributed agency and the collective social construction of entrepreneurial opportunity as abstract potentials that merit further research, Aldrich (2014) more directly proclaims the democratization of entrepreneurship. Similarly, Autio et al. $(2018,77)$ assert that digital affordances "do not operate spatially" and are "likely [to] challenge or even alter some spatial affordances at play within clusters and agglomerations."

\section{Four Modes of Value Creation}

By definition, digital enterprises use digital technologies to create value (Nambisan 2017). Compared with supply chains in analog manufacturing, digital enterprises focus more on resource orchestration rather than ownership, and on value creation rather than capture (Amit and Han 2017; Amit and Zott 2001; Foster and Graham 2016). The literature has established four modes of digital value creation: information processing, user interconnection, market intermediation, and digital production.

The most pervasive mode is information processing. In a digital world, meaningful (new) information can be created at low cost by editing, transferring, integrating, and analyzing existing information (Amit and Zott 2001; Shapiro and Varian 1998; Yoo, Henfridsson, and Lyytinen 2010; Zook and Grote 2017). Activities such as big data analytics, data science, machine learning, automation, algorithmic computing, and artificial intelligence are all facets of information processing.

The second mode is user interconnection, which exploits the network effects of some digital technologies, whereby the value of a good for a given user increases in proportion with 
the number of other users (Katz and Shapiro 1985). Network effects exist also for analog products, but they are more pervasive and significant for digital products (Shapiro and Varian 1998). User interactivity and interdependence can result in a "critical mass" adoption pattern, where technologies can fail if they do not reach a threshold of adoption while users can be locked in once the threshold is crossed (Markus 1987). Social networks and crowdsourcing platforms are key examples of such value creation.

Market intermediation exploits digital technologies to alleviate information asymmetries and reduce transaction costs in two-sided markets (Amit and Zott 2001; Eisenmann, Parker, and Van Alstyne 2006). More than just connecting buyers and suppliers, intermediaries also create market institutions-typically by guaranteeing transactions and safeguarding norms, thereby generating trust (Amit and Zott 2001; Autio et al. 2018). As with user interconnection, the value for a given user increases with others' adoption; however, for market intermediation, it is adoption on the other side of the market that benefits them (Amit and Zott 2001; Shapiro and Varian 1998). Some intermediaries can become sophisticated digital platforms: "building block[s]... which act as a foundation upon which other firms can develop complementary products, technologies or services" (Gawer 2011, 2). Digital platforms structure environments (or "ecosystems") within which a distributed set of typically small suppliers can conduct combinatorial innovations, which the platform partially controls and distributes to users (Gawer 2011; Yoo, Henfridsson, and Lyytinen 2010). Examples include app stores and ecommerce companies.

Finally, enterprises can engage in digital production: the creation of a digital artefact for sale and independent use. Software development falls into this category, both software as a service (SaaS) and turnkey and customized software provision (including outsourcing). While information processing, user interconnection, and market intermediation all depend on ongoing Internet-enabled interactions between enterprises and customers (Amit and Han 2017), digital 
production means that customers obtain a copy of the digital artefact and derive value from usage, even when disconnected from the supplier. Accordingly, this mode of digital value creation predates the rise of the Internet by several decades. Digital production typically differs from analog production (e.g., traditional manufacturing) because of the particular qualities of digital artefacts on the usage side, such as non-rivalry in consumption or near-zero cost of the second copy (Shapiro and Varian 1998; Thrift and French 2002), and the production side, such as particular dynamics of knowledge exchange and the ability to stack new layers of software on top of old ones (Riain 2004; Trippl, Tödtling, and Lengauer 2009; Gao and Iyer 2006). SaaS digital production will generally be more complementary with other modes of value creation compared to customized software. ${ }^{1}$

\section{Reaching Large and Distant Markets}

Many enterprises have effectively used globalized digital infrastructure to access distant markets. Software can be edited and disseminated at distance (e.g., located on the customer's device) at virtually zero cost (Kallinikos, Aaltonen, and Marton 2010), stretching the potential market reach and scope of digital enterprises beyond traditional boundaries (Amit and Zott 2001; Nambisan 2017). Moreover, the low cost of digital reproduction together with network effects result in enormous economies of scale and lock-in effects (Amit and Zott 2001; Shapiro and Varian 1998). This in turn leads to first-mover and "winner-take-all" advantages: digital enterprises invest heavily in quickly reaching a critical mass of users (Amit and Han 2017; Eisenmann, Parker, and Van Alstyne 2006).

${ }^{1}$ Consider a SaaS provider storing product components on its cloud server and allowing users to develop and share customizations through APIs, thus combining digital production, user interconnection, and information processing. 
Particularly exceptional potential exists for digital enterprises that exploit generativity (Henfridsson and Bygstad 2013; Huang et al. 2017; Nambisan 2017). This is because digital products and enterprises can themselves become an integral part of digital infrastructure (Davidson and Vaast 2010), leading to virtuous cycles of fast diffusion, lower entry barriers, and falling costs (Tilson, Lyytinen, and Sørensen 2010). Digital technology platforms and datadriven ventures are particularly well-situated to exploit generativity (Huang et al. 2017; Yoo, Henfridsson, and Lyytinen 2010), which has resulted in companies owning such products attaining unprecedented levels of market capitalization (Amit and Han 2017).

\section{Enterprise Location: A Blind Spot in the Digital Enterprise Literature}

In sum, information systems and strategy literatures highlight digital enterprises' ability to engage in particular modes of value creation while building on a globalized digital infrastructure, allowing some of them to scale quickly and reach distant customers. Yet, at a closer look, it becomes apparent that these insights are based on particular successful companies in a distinct set of locations. Many authors illustrate their arguments with exceptional US companies, such as Amazon, Google, and Uber (e.g., Amit and Han 2017; Amit and Zott 2001; Huang et al. 2017; Sussan and Acs 2017; Yoo, Henfridsson, and Lyytinen 2010). Even the foundational study by Amit and Zott (2001), attempting a more inclusive sampling, only analyzes publicly listed businesses in the US and Europe.

Relatedly, this literature tends to downplay the role of geography in bounding market opportunities. Amit and Zott $(2001,495)$ maintain that "[v]irtual markets have unprecedented reach because they are characterized by a near lack of geographical boundaries," and that the remaining analog barriers (e.g., cultural or language differences) "still appear to be vastly reduced relative to the traditional 'bricks-and-mortar' world." Autio et al. (2018) argue that digital affordances "do not operate spatially" (p. 77), that digital infrastructure is a "location nonspecific element" (p. 81), and that the "Internet's architectural trust mechanisms can 
potentially offer a near full substitute for social and relational trust that is non-localized and does not depend on geographical proximity" (p. 76). Ndemo and Weiss (2017) discuss what they consider a "digital entrepreneurship revolution in Africa" (p. 2), arguing that the "ICT revolution is a global and competitive phenomenon that is heralding a new paradigm of creativity and innovation in virtually every part of the world" (p. 4), which could give countries like Kenya "the opportunity... to take on an all-new role in the digital economy" (p. 462). It appears that digital infrastructure in particular and digital technologies in general are often construed as globally homogenous, ubiquitous, and openly accessible/inclusive entities (Aldrich 2014; Sussan and Acs 2017; Tilson, Lyytinen, and Sørensen 2010; Greengard 2010). This results in the implication that any enterprise with an Internet connection should have equal access to the same opportunities (cf., Nambisan 2017, 1046; Greengard 2010), and to the same vast, global markets.

However, such assertions and implications clearly conflict with longstanding findings of economic geographers, who have found both digital infrastructure and digital production activities to be highly unevenly distributed across space (Leamer and Storper 2001; Malecki 2002; Malecki and Moriset 2007; Ojanperä et al. 2017; Pickren 2018; Zook 2000, 2005). It is particularly doubtable that African digital enterprises would be able to seamlessly build on digital infrastructure, given African businesses' historically limited ability to exploit digital technologies for local value creation and capture (Donner and Escobari 2010; Foster et al. 2018; Murphy and Carmody 2015), and given the continent's overall thin levels of integration in the global digital economy (Carmody 2013; Murphy, Carmody, and Surborg 2014).

This article thus aims to examine how the unevenness of the global digital economy translates to the concrete micro-level pursuit of opportunity by African digital enterprises. We use a comparative geographical lens to explore digital entrepreneurship in Africa as a newly forming economic practice and development process that is at the same time local and global. 
We thus heed to Nambisan's $(2017,1046)$ call to explain "how and why the 'same' digital infrastructure... has different entrepreneurial outcomes in different contexts." We ask two interrelated research questions:

\section{How do African digital enterprises create and capture value?}

2. Which markets are African digital enterprises able to reach, and why?

\section{METHOD}

The goal of this study was to expand existing theory on digital enterprise, improving its applicability to global economic peripheries. Our overall methodological choice was thus inductive theory development based on case studies (Yin 2009). African cities appeared suitable for case selection because they were extreme cases on theoretically relevant dimensions compared to geographical contexts in existing work (Flyvbjerg 2006). Namely, African nations have a particular Internet connectivity history, with West and East Africa being the last major regions on the planet to be connected by submarine fiber-optic cables (Graham, Andersen, and Mann 2015). More broadly, Sub-Saharan Africa is only poorly integrated in global digital production networks (Carmody 2013; Ojanperä et al. 2017).

\section{Data Sources and Case Selection}

Our own prior work on the digital economies of a number of African countries (references omitted for peer review) has sensitized us towards methodological challenges in this region, especially the lack and low reliability of secondary economic, financial, and business data. Many digital enterprises fail to register as a business due to burdensome procedures, even the largest digital enterprises are not typically listed with stock exchanges, and enterprises seeking foreign investments will tend to incorporate in the US or Mauritius. Rather than attempting a continent-wide analysis based on secondary case study data, we therefore opted for primary data collection in four cities. Systematic comparisons between cities (including within-case process tracing and cross-case pattern matching) would help us 
rule out idiosyncrasies of any given case and increase the external validity of our claims across economically peripheral regions of the world (Yin 2009).

In order to collect a diverse sample of digital enterprises, we identified contexts that had only recently been connected with affordable broadband Internet (ruling out most nations in South and North Africa), but which also had an active digital entrepreneurship landscape. Based on our experience, online media articles, and reports by development organizations and consultancies, we chose Lagos (Nigeria) and Nairobi (Kenya). We also included Kigali (Rwanda) to examine a landlocked country with a much smaller domestic market, but which otherwise boasts high-quality Internet infrastructure, physical infrastructure, and policy support. Following preliminary analysis of data collected in these cities, we conducted further fieldwork in Accra (Ghana).

\section{Fieldwork and Sampling of Digital Enterprises}

Our unit of analysis was the "African digital enterprise," which we defined as the enactment of an entrepreneurial process (see definition above) by an economic actor (mostly organizations but including individuals and non-organizational collectives), generating a product or service whose value arises by virtue of at least one of the four modes of digital value creation that we identified from the literature. We defined an enterprise as "African" when its value-creating, owned or controlled, physically embodied assets were primarily located in Africa. Assets were broadly understood to include people (founders, managers, employees), hardware technology (computers, servers), and proprietary infrastructure (offices, storage facilities, etc.).

Complete and reliable databases of African digital enterprises were unavailable, precluding rigorous quantitative analysis and representative sampling. In order to support generalized explanatory claims, we attempted to purposefully sample enterprises that would be as diverse as possible on theoretically relevant dimensions (Yin 2009). We thus increased 
variation along observable enterprise attributes, such as number of employees, revenue, age, sector, founder nationality and educational background, investments raised, etc.

We ultimately chose to pursue a breadth-oriented sampling and qualitative comparative analysis strategy. During nine weeks of fieldwork in early 2017 and three additional weeks later in the year, we conducted 68 in-depth semi-structured interviews with founder entrepreneurs, who we identified through a purposive snowball sampling approach. We identified digital enterprises from other studies, online media, and our own contact network, yielding pre-fieldwork lists of around 30 enterprises per city. We then prompted participants and local contacts to name other local digital enterprises with attribute combinations we had not yet sampled, focusing on size, age, and sector. Participants were very responsive, allowing us to conduct almost all the interviews we felt were necessary to increase sample diversity.

Some of the interviewed entrepreneurs had founded multiple firms or one firm with multiple discernible units. 68 interviews thus resulted in 73 cases of digital enterprises. While this sample is not representative in a strict sense, we interviewed a large and diverse set of founders to reflect African digital enterprises in a comprehensive way, thus increasing our confidence that we captured the most significant patterns in each field site.

\section{Coding and Analysis}

All interviews were transcribed and analyzed with NVivo. The analysis consisted of two main components: coding all enterprises according to pre-defined theoretically relevant categories, and qualitative thematic analysis. Category coding served to reduce rich and complex data and discover overall patterns, while thematic coding was used to elicit underlying detail and causal chains that explain the patterns (Miles and Huberman 1994).

In line with our research questions, for each enterprise, we first coded the primary mode of value creation and the primary geographical market scope. Our interviews elicited this information through explicit questions and follow-up prompts, making it easy to determine 
these categories based on transcripts. The four categories for value creation were derived from the literature: "Information Processing," "User Interconnection," "Market Intermediation," and "Digital Production." We discovered complementarities for certain modes of value creation (cf., Amit and Zott 2001), leading us to also code secondary modes.

We coded enterprises' primary geographical market scope as "Local" when most customers were located within the enterprise's home nation and "International" when they were abroad. We also coded secondary geographical market scopes in cases where we found smaller but significant customer segments in other places than the primarily targeted locations.

As further theoretically relevant geographical patterns transpired during the coding, we fine-coded "Local" into "Urban" (customers in the same city or in other major cities of the country), "Rural" (customers residing in rural areas, such as farmers), or "National" (customers spread throughout the country). Enterprises coded as "International" were further divided into "International-Global North" or "International-Pan-African." The "International-Global North" category seemed to include a number of idiosyncrasies rather than clear patterns, leading us to further attribute specific customer segments such as "Development organizations" or "Diaspora."

For thematic coding, we proceeded according to standard practice for iterative inductive/deductive theory development, starting from a broad analytical framework, which we extended, deepened, and refined as analysis progressed (Miles and Huberman 1994; Strauss and Corbin 1990). We thus coded details to specify our explanandum (value creation and geographical market reach), and then derived rich sets of emergent themes to capture entrepreneurial processes, thereby eliciting plausible explanations for our observations. Further, we derived themes specifying contextual variables affecting digital enterprises, such as technological and transportation infrastructure, human capital, access to finance, support from incubators, etc. 
What we ultimately referred to as "localization" became an extremely rich theme. We iteratively divided and collapsed subthemes to capture enterprise strategies in more detail, which finally resulted in subthemes, namely "Differentiation, especially from international competition," "Adapting to local markets," and "Learning from concrete experiences of failure." This coding scheme stabilized, which we interpreted as theoretical saturation (Strauss and Corbin 1990). We then used the categorical coding to identify particular groups of enterprises, analyzing group-specific patterns in entrepreneurial processes in more depth (e.g., International vs. Local, or Local-urban vs. Local-rural).

Reliability and validity of our findings was established by a number of cross-validations, helping us to crystallize generalizable patterns and to rule out alternative explanations and context-specific factors. Namely, we compared patterns across enterprise clusters (grouped by attributes such as sector), and conducted extensive cross-contextual comparisons. In particular, we tested the fit of the initially developed theory with data from the Accra case study, which was collected nine months later than the data for the other case studies. Accra also represented a digital enterprise context with a level of advancement between Kigali on the one hand and Nairobi and Lagos on the other. The arguments developed based on our initial thematic analysis were generally confirmed, while some nuance was added (such as two Ghanaian companies which tried to address global markets but having to scale back following competition from the US and Europe).

\section{FINDINGS}

In this section, we report direct observations and first-level analysis. We first describe the emergence of digital infrastructure in the four cities under observation, before focusing on enterprise-level analysis. We outline the sampled enterprises' modes of digital value creation, market geographies, and a generalized account of their opportunity recognition and pursuit. 


\section{Local Markets for Digital Products}

Across all four cities, participants consistently spoke of digital entrepreneurship as a new economic practice, with the oldest local firms typically established in the 1990s or early 2000s, starting with customized software development for local corporate clients. With increasing availability of mobile phones throughout the 2000s, value-added mobile service providers then started to emerge, targeting a mass consumer audience. These companies offered simple products like ringtones or bulk text message delivery. A few fixed-broadband Internet service providers usually served a narrow client base in cities (e.g., banks or multi-nationals).

From around 2010, mobile broadband became more widely available, enabled by the arrival of fiber-optic submarine cables on the shores of West and East Africa. In parallel, mobile money services were introduced by mobile network operators, with MPesa in Kenya as a technological frontrunner. Such applications are usually USSD and SMS-based, allowing users to have a digital wallet and transfer money. While the overall success of mobile money is undeniable, problems include lacking interoperability between operators. Another complaint from entrepreneurs concerns malfunctioning or lacking interfaces, as well as poor reliability:

We have the easiest possible way for making a[n MPesa] payment and still, it is pretty arduous. If you look at the payment conversion rates, they are between $15-20 \%$, meaning that $80 \%$ of people drop out during the payment cycle. (Entrepreneur in Nairobi)

With increasing mobile broadband coverage, cheap smartphones became more common especially among wealthy and middle class populations in cities and peri-urban areas. However, interviewees complained that local users were typically extremely price-sensitive and lacked exposure to digital technology:

Customers don't want to have smartphones and... if you're above average price, nobody will ever take you... There's just so many unknowns here. The phones are worse. The Internet speeds are not effective. People don't have a history of using apps. Many people don't have email... People have extremely low disposable income. (Entrepreneur in Kigali)

Accordingly, local clients typically demand cheap and simple digital services (e.g., modifying WordPress templates), and only very few applications have reached wider 
audiences. Common features appear to be zero or transaction-based pricing, low data consumption, sufficient functionality on feature phones or low-level smartphones (e.g., through offline usability and SMS/USSD integration), and the fulfilment of a basic, widespread need (such as interpersonal communication). Accordingly, aside from applications offered by mobile operators, only WhatsApp and Facebook (often in its low-bandwidth "Zero" and "Basics" versions) have reached significant user populations outside of major cities.

\section{Enterprises' Use of Digital Infrastructure}

While local digital enterprises had not typically reached national audiences via the Web, they had begun using other elements of global digital infrastructure. Many entrepreneurs reported that they primarily used Facebook for digital marketing, and WhatsApp and SMS to communicate with existing customers (for example, sending confirmations and updates):

So we decided, let's just take a few pictures and post them on Facebook and see if anyone buys... there was such an interest! ... Facebook has always helped us actually... because a lot of young people, that's what they use, and then you direct them to [our own web]site. (Entrepreneur in Nairobi)

We also saw digital enterprises in our sample employing digital infrastructure for managing internal processes, using cloud and SaaS platforms originating mostly in Silicon Valley. Most enterprises relied on services like Windows, iOS, Google products, WhatsApp, Microsoft Office, Amazon Web Services (AWS), PayPal, WordPress, GitHub, Slack, and Dropbox. Further, many African digital enterprises outsourced software development to India and Europe (Poland in particular). This typically became necessary following a lack of local software engineering capacity:

[The prototype] was developed in Poland [through a] freelancer website... I found the designer... the engineer, [and] the second engineer on Elance [a major online labor platform]. I don't have any engineer here... that type of knowledge [is not available] in Rwanda. (Entrepreneur in Kigali)

This implies that the availability of the Internet in Africa appears to have mainly fueled the uptake of digital products which have become part of the global digital infrastructure: consumers adopted Facebook and WhatsApp, enterprises started using cloud-enabled 
solutions, and both relied on mobile broadband hardware (including wireless network technology mostly from Europe and cheap devices from East Asia).

\section{Patterns of Digital Enterprise Value Creation}

Once digital infrastructure became available with improved broadband around 2010, the number and diversity of locally based African digital enterprises increased notably. Very few enterprises in our sample $(n=3)$ were founded earlier: just one corporate software development firm, one job search portal, and one bulk SMS provider. All other enterprises $(n=70)$ started in 2010 or later, relying on digital infrastructures and identifying increasing domestic technology adoption as an entrepreneurial opportunity. Market Intermediation ( $\mathrm{n}=23)$, Information Processing $(n=22)$, and Digital Production $(n=23)$ were the dominant primary modes of value creation in our sample, with User Interconnection being rarer $(n=5)$. Most enterprises identified opportunities in digitizing traditionally analogue processes in local economies:

I think initially you go to customers, understand what they want and just computerize the manual operation into what they were currently doing. So it was nothing new, just automating what they already had.

Market Intermediation typically consisted of connecting small service providers with consumers; it was therefore prevalent in sectors like e-commerce, ride sharing, agricultural supply chains, and job search. Information Processing was prevalent where collection or aggregation of private, proprietary, sensitive, or complex information could be used to derive new insights, such as in logistics or the financial sector:

Nigeria is an informational data desert... Being able to get that data, mak[ing] it somewhat real-time, is really valuable for [our customers]... The lesson we've learned is, we make it modular... There's the reporting module and the visualization module... [That's] how we get entrenched in their system. (Founder of a logistics digital enterprise)

Digital Production consisted mainly of software development for organizations (both customized and SaaS), such as enterprise resource planning systems (ERPs). User Interconnection included four information crowdsourcing applications and one interactive smartphone app. 
Secondary modes of value creation were dominated by Information Processing $(n=33)$. More than two thirds of the sampled enterprises $(n=55)$ thus used Information Processing either as a primary or secondary mode of value creation, confirming our expectation that it would be prevalent. Information Processing was used in particular to complement Market Intermediation and User Interconnection (see Table 1). This would also be unsurprising for digital enterprises in the Global North: when users interact with each other through a digital product, it is a logical next step to process the information that is generated as a by-product.

\begin{tabular}{|c|c|c|c|c|c|c|}
\hline & & \multicolumn{4}{|c|}{ Primary value creation } & \multirow[b]{2}{*}{ Total } \\
\hline & & $\begin{array}{l}\text { Information } \\
\text { Processing }\end{array}$ & $\begin{array}{c}\text { Market } \\
\text { Intermediation }\end{array}$ & $\begin{array}{c}\text { Digital } \\
\text { Production }\end{array}$ & $\begin{array}{l}\text { User Inter- } \\
\text { connection }\end{array}$ & \\
\hline \multirow{6}{*}{ 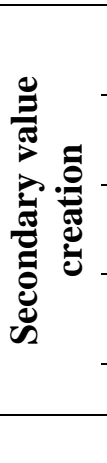 } & $\begin{array}{l}\text { Information } \\
\text { processing }\end{array}$ & -- & 21 & 8 & 4 & 33 \\
\hline & $\begin{array}{l}\text { Market } \\
\text { Intermediation }\end{array}$ & 6 & - & 1 & 0 & 7 \\
\hline & $\begin{array}{l}\text { Digital } \\
\text { Production }\end{array}$ & 2 & 2 & -- & 0 & 4 \\
\hline & $\begin{array}{l}\text { User Inter- } \\
\text { connection }\end{array}$ & 1 & 0 & 0 & - & 1 \\
\hline & None & 13 & 0 & 14 & 1 & 28 \\
\hline & Total & 22 & 23 & 23 & 5 & 73 \\
\hline
\end{tabular}

Table 1: Primary and secondary modes of value creation

However, in our sample of African digital enterprises, Information Processing by Market Intermediators consisted less of analytics and automation, and more of basic digitization: enterprises were making available previously analog information about end users and informal service providers, complementing this with only lightweight automation and analytics, if any:

It's not really e-commerce... our market had not really matured to the point where people can confidently get out their [credit] cards, or go to a website and then buy something from there and have it delivered... We've not gotten to that full or high-level automation. (Entrepreneur in Accra)

\section{Local Markets, Elusive Scale}

Our data were rather unambiguous in suggesting that African digital enterprises mostly targeted local markets. Usually, enterprises identified a market niche that existed in their geographical proximity and deployed digital technologies to address it: 
I saw that there was a need of having a market for software... We see that people were looking for... a kind of inventory management system, but at that time, there was no Rwandan company who was specialized in that. (Entrepreneur offering localized ERP software)

All four modes of digital value creation were thus overwhelmingly locally focused (see

Table 2). Only a few enterprises focusing on Digital Production targeted the Global North, namely four outsourcing providers and one globally operating SaaS provider. 


\begin{tabular}{|c|c|c|c|c|c|}
\hline & $\begin{array}{l}\text { Information } \\
\text { Processing }\end{array}$ & $\begin{array}{l}\text { Market Inter- } \\
\text { mediation }\end{array}$ & $\begin{array}{l}\text { User Inter- } \\
\text { connection }\end{array}$ & $\begin{array}{c}\text { Digital } \\
\text { Production }\end{array}$ & Total \\
\hline International & 2 & 1 & 1 & 6 & 10 \\
\hline Global North-Outsourcing & & & & 4 & 4 \\
\hline $\begin{array}{l}\text { Global North-Software as a } \\
\text { service }\end{array}$ & & & & 1 & 1 \\
\hline Pan-African & 2 & 1 & 1 & 1 & 5 \\
\hline Local & 20 & 22 & 4 & 17 & 63 \\
\hline National & 8 & 4 & & 3 & 15 \\
\hline Rural & 1 & 2 & 1 & 1 & 5 \\
\hline Urban & 11 & 16 & 3 & 13 & 43 \\
\hline
\end{tabular}

Table 2: Dominance of local markets as a primary focus for African digital enterprises

In fact, barriers existed already at the sub-national level, with most locally oriented enterprises serving only proximate urban contexts. This was because enterprises tended to identify problems in their vicinity, but also because digital value creation depended on a minimum degree of technology readiness among users, which typically existed only in cities. Promising smartphone and Internet adoption figures often did not reflect real market potentials:

All these numbers around these 30 million people being connected, or according to Google, 23 million Kenyans-it's bullshit, it's just ridiculous... If you look at the Nigerian markets, you have a lot of guys who saw it as an opportunity and now they're pulling out because the promise of the market is not there. (Entrepreneur in Nairobi)

Cross-border scaling was envisioned but proved elusive for many enterprises. The most common reason given was that enterprises needed to first perfect their product in local markets to be able to raise investments or generate significant revenue. Indeed, this was the experience of the few sampled digital enterprises that had Pan-African market reach:

Africa is very fragmented and it comes with its own bottlenecks. In the early stages, you don't want to keep all the complexities... I remember, when we wanted to set up in Ghana, it was hell. Just Ghana! ... Win your market, make a lot of cash, then you can go to other markets and use that cash to go fight. But if you're still bleeding in your local market, I'd advise that [you] stay! [laughter] (Entrepreneur in Nigeria)

The founder of another Pan-African enterprise added that cross-border scaling hinges on customer referrals:

[The expansion beyond Kenya] happened in the same way [as the domestic expansion]. We got one customer [who] was well-connected... so he liked what I used to do, and he was a good promoter for us... So from there I got exposure to five [African] countries. 
Finally, secondary customer segments were examined for evidence of enterprises targeting international markets. We found a higher number of incidences than for primary customer segments $(n=18)$, but these cases were rather idiosyncratic. In particular, development organizations were sometimes targeted by enterprises with a local primary market scope $(n=6)$, because they were a welcome if erratic alternative revenue source. For instance, one Nigerian digital enterprise used its unique local understanding to make sense of available datasets, delivering analytical reports to development organizations. A few enterprises $(n=3)$ were able to use pre-existing relationships with contacts abroad to strike ad hoc deals. Two money transfer services and one investment broker targeted the diaspora, but adoption numbers remained low. In one case, a smartphone app was offered through the Android Play store, without this amounting to a lasting uptake abroad or to revenue generation. In another outlier case, a French digital entrepreneur found that his initial focus on Ghana (where he was based) was misguided, illustrating the importance of culture and language:

[In] Côte d'Ivoire... it was in French, so it was a thousand times easier... As a matter of fact, we closed more deals in Ivory Coast in six months than we did in three years in Ghana. (French digital entrepreneur in Ghana)

In only one case did an African digital enterprise compete in a global digital market with enterprises from the Global North. This enterprise offered a specialized integrative e-commerce platform for online shops, with customers mainly in the US, the UK, Australia, and several European countries. The founder reported that growth had been satisfying at first while it soon stagnated. He felt that, even in a market that is ostensibly entirely digital, geographical distance to customers and the enterprise's location mattered greatly:

Can we compete with some of the companies that we started out with back in the day? The answer is no. The technology probably didn't scale the way we wanted it to be, customers didn't go the way we wanted; revenue also. [Our competitors were more successful because of their] proximity to the market, proximity to investors, proximity to networks within maybe [the] US, or the Valley, or wherever they are - all those things count. Also, sometimes, just even common simple time zone difference affected the business... We didn't have the resources to plan customer management, sales. 
In sum, African digital enterprises were not able to surpass local markets based on the distance-bridging potential of digital technologies alone. Instead, they required various combinations of time, resources, trust-based relationships, unique local knowledge, and cost advantages. This was true even when outputs were digital in nature — and thus in theory could have been disseminated easily to anywhere in the world-as in the case of software outsourcing.

\section{Grappling with the Analog and Local Through Iterative Adaptation}

Our 68 interviews with digital entrepreneurs from across four African countries (unsurprisingly) yielded a diverse array of entrepreneurial journeys; however, there were patterns that generalized across the dataset. We saw that digital enterprises typically became sustainable only after a multi-year process of iterative adaptation, which included learning from failure, adapting to the specificities of local markets, and differentiation from competitors (including those from the Global North). It was this adaptation process that tied most enterprises deeply to local contexts: digital enterprises had to localize in order to survive.

Firstly, digital enterprises depended on in-depth learning from and interaction with customers. Adjustments became necessary when markets turned out to be different in nature than originally expected:

We have actually [our own] very, very elaborate model around all these markets... People don't really... know what they don't know. The crazy thing with the investors was that they had no idea for basically what we understand about this market, how deep we have gone. (Entrepreneur in Nairobi)

In-depth learning proved more challenging when enterprises targeted foreign customers.

A Ghanaian entrepreneur recounted an unsuccessful attempt:

Our initial target was that... we could sell this product in Europe... Unfortunately, that couldn't happen because the sort of input... that was required didn't happen. Getting the product in front of potential customers, getting focus groups, getting people to test out, even for free-we couldn't do that.

Receiving and adapting to market signals was only possible when the targeted customers were accessible. This accessibility, however, depended on a richer and more sustained 
engagement than could be afforded by digitally mediated communication. Local markets thus became a more feasible choice for African entrepreneurs, either because they were already more familiar with them or because they could access them more effectively than foreign competitors:

We were [initially] doing this, "Let's do an Uber for motorcycle taxis." ... The idea was like, let's just have 10 software devs and crack this code... Uber has more than a thousand software developers, so if we're trying to chase Uber, it's just going to be a game of defeat... Understanding from day one that you can't make the ideal team, or the team you'd be able to do in the West, is an important realization of how the company's going to grow... You can't make a pure software company here. (Founder of a ride sharing enterprise)

Secondly, African digital enterprises necessarily had to negotiate their immediate surroundings. They could leverage a globalized digital infrastructure, but also had to manage the low capacity of the local instantiation of this infrastructure, as well as major limitations in analogue infrastructures. As a result of this challenging positioning, African digital enterprises were unable to specialize in the development of technology, or work at the technological cutting edge:

Internet solutions in Nigeria are still typically O2O, offline to online... It's market-driven, not really technology-driven... If you look at Jumia [the largest e-commerce enterprise in Africa], for example, they have 8,000 guys on the streets. The technology is never the business, at least in Africa. (Entrepreneur in Nigeria)

Instead, African digital enterprises were forced to address a number of time- and effortconsuming challenges that would not be faced by digital enterprises in the Global North:

The payments problem has a lot of different sides to it. What we did essentially, [we] collect cash on your behalf as a merchant... so we're like a bank on the field... We have insurance... if a driver gets attacked, but we also have a lot of stuff built into our training on how our drivers should make sure that they don't get robbed. (Entrepreneur running a delivery enterprise in Nigeria)

In sum, almost none of the African digital enterprises in our sample created a product that existed purely in the digital realm and was independent of their physical location (e.g., software for use by Internet users anywhere). Ultimately, digital technologies could not obviate their embeddedness in African contexts, which in turn compelled them to turn this embeddedness into a strategic differentiator. As a result, most enterprises over time integrated 
digital and analog — and thus localized — value creation. Common examples of analog value creation were face-to-face outreach to customers, soft skills and technical training for staff, and the establishment of supply chains (e.g., handling infrastructure, payments, and logistics).

\section{DISCUSSION}

The findings we presented in this article challenge previous scholarship that treats digital entrepreneurship as a globally homogenous, or homogenizing, phenomenon (Aldrich 2014; Autio et al. 2018; Sussan and Acs 2017), and they qualify assertions that digital enterprises generally face fewer structural boundaries than traditional ones (e.g., Amit and Zott 2001; Nambisan 2017). To be sure, this prior work has never directly challenged economic geographers' rejection of the "end of geography" thesis (Leamer and Storper 2001; Zook 2001; Malecki 2002; Thrift and French 2002) — it has not argued that distance is dead or that spatial agglomerations are rendered entirely obsolete (cf., Autio et al. 2018). Still, this new body of scholarship maintains that digital enterprises, as a particular kind of economic actor, are able to coordinate production and disseminate products in relatively unbounded ways. Yet, this paper shows that geography and location matters also at the enterprise level of analysis. Specifically, the way in which digital infrastructure enables entrepreneurial opportunity is itself location-dependent - and thus never exactly "the same" in two different places (cf., Autio et al. 2018; Nambisan 2017). While our data confirm that digital infrastructure has become an external enabler of entrepreneurship also in African cities, digital enterprises there continue to face significant barriers to making productive use of this infrastructure and to reaching distant markets.

African digital enterprises are unable to employ digital technology in precisely those ways in which it allows some enterprises in economic cores to scale widely. They are neither able to address significant distant or "virtual" markets, nor can they typically exploit critical 
mass effects, nor do they become enmeshed in the generative growth of global digital infrastructure. Among the enterprises in our sample, the few that served distant customers engaged primarily in software outsourcing. Yet, these few cases relied heavily on pre-existing individual relationships and other non-digital factors, leading to more limited growth.

\section{Digital Enterprises (Have to) Start Somewhere}

Our findings confirm that an African digital enterprise, like any enterprise, pursues opportunity through an evolutionary, context-dependent process, during which it iteratively probes into perceived opportunities and adjusts its pursuit according to market signals (Alvarez, Barney, and Anderson 2012). As with analog enterprises, this process has to start somewhere in physical space, and both a digital entrepreneur's perceptions and the signals they receive are necessarily affected by the enterprise's geographical location.

In our sample, African cities induced localization as a specific path dependency for the strategic pursuit of opportunity. Opportunity appears to usually be discovered in economic peripheries when entrepreneurs identify a longstanding local problem, which they aim to address through newly available digital technology, or when they come to see their location as a strategic advantage (e.g., allowing for differentiation from international competitors). As entrepreneurs probe deeper into these geographically defined opportunities, they find that local adaptation of digital technologies represents a small but tangible market potential, which over time induces enterprises to increasingly specialize in localization.

However, localization also systematically steers enterprises away from the scaling and distance-bridging potentials of digital technologies. For one, when enterprises gear their products towards local markets, this usually decreases the relevance of those products for distant ones. Yet, given local customers' low numbers, limited capacity, and minimal willingness to pay, markets tend to be too small to trigger critical mass effects or other scale economies. This is problematic especially for enterprises in small countries (cf., Normann and 
Hanson 2018). Enterprises in Rwanda were smaller and less likely to reach markets abroad than those in Kenya and Nigeria, despite Rwanda's advanced Internet infrastructure. Exponential growth as described by Huang et al. (2017) for a Chinese enterprise is not imaginable in Africa, because national markets are too small and Pan-African markets too fragmented to support user-based and data-driven growth.

Moreover, the digital enterprises in our sample showed that localization in economic peripheries depends on integration of digital and analog value creation. The enterprises in our study built user trust in technology through extensive face-to-face interactions, developed their own physical infrastructure and logistics, and conducted their own staff training. Localization for African digital enterprises meant that they were partially insourcing analog value creation (cf., Christensen, Ojomo, and Bever 2017; Khanna and Palepu 1997). This is a key difference to digital enterprises in the Global North, which can take supportive external analog structures for granted. The need for analog integration also explains the outsize role of large cities (like Nairobi and Lagos) as markets: analog integration may be feasible in proximate local urban contexts while it is often cost-prohibitive in rural parts of low-income countries.

Even if enterprises discover opportunity at distance, they will likely receive negative signals from the market, as there will typically be superior competition from elsewhere in the world. The African enterprises in our sample which nurtured global aspirations - ranging from outsourcing companies through Android apps to SaaS providers - all had to eventually give up on or scale down their ambitions.

Ultimately, most digital enterprises that launch in economic peripheries may find localization to be the optimal strategy given their geographical starting point. Yet, it is also evident from our data that localization sets digital enterprises on more restricted growth paths, systematically precluding them from the most significant scaling opportunities. Accordingly, 
while peripheral digital enterprises can certainly be sustainable and successful, it appears that their market scope and scaling abilities are bound to be geographically confined.

\section{An Enterprise-Location-Based Theory of Digital Market Geographies}

Our findings provide further evidence that enterprises benefit from partaking in the generative scaling of digital infrastructure (Huang et al. 2017; Tilson, Lyytinen, and Sørensen 2010; Yoo, Henfridsson, and Lyytinen 2010). That said, our data highlighted the exclusive nature of generative scaling rather than its ubiquity. The digital enterprises in our sample were all users of digital infrastructure, but they rarely contributed to creating it: no new digital innovations were building on theirs, especially not in other parts of the world and the Global North.

While contemporary digital economic activity relies on engagements with previous layers of digital infrastructure (Benkler 2006; Tilson, Lyytinen, and Sørensen 2010), it does not follow that any such activity automatically contributes a new layer for others to build on. Instead, for digital enterprises to exploit generative scaling, they have to occupy strategic positions within wider digital product architectures. Studies of digital technology platforms have shown how some platforms are able to make other digital innovators create value for them, by establishing partially controlled ecosystems and exclusively owning central interconnection points, such as relationships with users (Amit and Han 2017; Eisenmann, Parker, and Van Alstyne 2006; Yoo, Henfridsson, and Lyytinen 2010). Our study suggests that digital enterprises in peripheries may be systematically confined to the position of platform users rather than platform creators. Digital platform usage may be an important form of digital entrepreneurship in its own right (Sussan and Acs 2017), but our findings illustrate that users can be excluded from reaping the benefits of platforms' generative scaling.

Paradoxically and ironically, it is precisely the enormous distance and scaling bridging potential of digital technology that is insulating African digital enterprises within their 
particular operating locations. In markets of digital products which require no local adaptation, African enterprises cannot compete with incumbents, often located in Silicon Valley, which are indeed already operating at planetary scale. Products like WhatsApp, Facebook, Slack, or GitHub have been able to reach into every digitally connected part of the world. Although none of these enterprises has a noteworthy physical presence in Africa, they have established digital, layered products that build entirely on other digital infrastructural layers, which are globally standardized and accessible, such that scaling is possible with almost no analog constraints, except for those imposed by hardware (Yoo, Henfridsson, and Lyytinen 2010). For instance, WhatsApp relies on the Internet, telecommunications infrastructure, standardized devices, interoperability standards, operating systems, character sets, and fonts. Through such digitalonly strategies, these rare enterprises have either won global winner-take-all digital markets (Huang et al. 2017; Markus 1987; Shapiro and Varian 1998) and/or serve as key global digital infrastructures themselves (Tilson, Lyytinen, and Sørensen 2010). Due to unfettered firstmover advantage and generativity scaling, the more digital (and thus layered and scalable) products are, the less likely they are to be created and controlled by digital enterprises starting in places where access to the necessary financial and human resource will be more difficult (cf., Zook 2005).

Conversely, digital products that depend on analog or locally specific digital infrastructure have not had the same global reach. For instance, while Amazon's cloud offering (AWS) is available in most parts of Africa, its delivery services are not available anywhere on the continent. In the latter case, Amazon depends on analog infrastructures that are not globally standardized and expensive to create, such as logistics systems, payment channels, credit scoring agencies, etc. It is where digital products depend on analog infrastructures that are globally incomplete that peripheral digital enterprises can enjoy a competitive advantage: 
foreign digital enterprises will not find it cost-effective to deal with local analog constraints worldwide.

Our findings therefore lead us to theorize that, globally, the more a digital product category lies on the layered end of the spectrum of layered modular design architectures (Yoo, Henfridsson, and Lyytinen 2010), the lower the number of digital enterprises making and owning products in this category, and the more geographically concentrated those enterprises will be (for example, in Silicon Valley). On the other hand, the more a product category lies on the modular end (e.g., digitizing an existing analog process), the more numerous will be the digital enterprises making and owning products in the category, and the more geographically distributed they will be across all places connected to broadband Internet.

This theory allows for differentiating enterprise scaling that is more or less constrained by localized digital infrastructure and by the analog world. For instance, Amazon is mischaracterized as an enterprise which "has no physical outlet" (Sussan and Acs 2017, 56); instead, it is a digital enterprise which blends a proprietary digital technology platform (which itself scales generatively) with an existing analog infrastructure (logistics, regulations, suppliers, consumers' hardware, credit cards, etc.). Accordingly, our theory explains why the reach of financial technology (e.g., PayPal), ride sharing (e.g., Uber), and e-commerce providers (e.g., Alibaba) has been increasingly global but without reaching every Internetconnected place. Local competitors in these digital product markets can persist (e.g., LittleCab vs. Uber in Nairobi, or Paga vs. PayPal in Nigeria), while this is not the case for, say, social network sites (e.g., now-defunct Pan-African Mxit vs. Facebook and WhatsApp). Massive digital scaling effects exist within the globally standardized digital layers of the former products, but they do not entirely overwhelm analog scaling constraints, allowing local solutions to survive wherever those constraints are too burdensome for the foreign entrant. 


\section{Which Digital Enterprise, Where?}

Broadly, we conclude from our study that digital market boundaries are in large part determined by an enterprise's local context, especially during the start-up phase. An enterprise founded in Silicon Valley or Shenzhen may well be able to exploit the growth and scalingenabling features of digital technologies, but for an enterprise launched in Kigali, this opportunity will prove more elusive.

This has implications for previous and future scholarship. Prior work in the strategy and information systems literature has greatly contributed to our understanding of digital enterprises; however, we find that several claims regarding their scaling and distance-bridging capabilities may only apply to a rather limited subset of digital enterprises, namely those that are located in places where access to resources can rival the access of businesses located in established clusters (currently in the US, parts of Europe, and South and East Asia). This is important because strategy implications derived from this work may not apply to the vast majority of digital enterprises around the world, especially not to those in economic peripheries. An African digital enterprise may be ill-advised to pursue a user-based and datadriven "growth on steroids" strategy (Huang et al. 2017), a digital platform strategy (Eisenmann, Parker, and Van Alstyne 2006), a generativity scaling approach (Tilson, Lyytinen, and Sørensen 2010; Yoo, Henfridsson, and Lyytinen 2010), or a resource orchestration strategy (Amit and Han 2017), because none of these options may be feasible simply by virtue of the enterprise being located in Africa. Practically all entrepreneurs we interviewed were adamant, for instance, that African digital ventures have to focus on revenue (i.e., value capture) from day one (cf., Amit and Han 2017). Foreign entrepreneurs pursuing a "Lean Startup," usergrowth-based, and data-driven approach usually began struggling soon after launch, and had to adjust their strategy accordingly. 
In sum, future scholarship should not treat digital infrastructure as an affordance that will allow any enterprise anywhere to transcend its previous bounds. A geographically aware theory of boundedness is needed, not to negate the transformative potential of digital infrastructure, but to acknowledge the way that it is contingently harnessed through layers of infrastructures and analog local contexts.

Since digital enterprises always have a physical manifestation (staff, offices, computers, conversations with clients, etc.), digital affordances can never fully allow them to transcend their own economic geographies (Leamer and Storper 2001; Malecki and Moriset 2007). We thus advise against thinking of digital affordances as virtual, ubiquitous, and aspatial counterforces to space-bound mechanisms such as agglomeration (cf., Autio et al. 2018; Greengard 2010), and instead suggest that digital affordances are themselves actor- and geography-dependent. Digital affordances cannot affect entrepreneurship without an entrepreneurial actor who either exploits them or is constrained by them, and this entrepreneur necessarily exists in some physical local context. Digital infrastructure itself is not "level," and thus never exactly "the same" in two different contexts (cf., Nambisan 2017; Greengard 2010). Ultimately, locational context, agency, and digital affordances are intertwined, and they shape the discovery and creation of economic opportunity in conjunction. 


\section{REFERENCES}

Aldrich, Howard E. 2014. "The Democratization of Entrepreneurship? Hackers, Makerspaces, and Crowdfunding." Academy of Management Proceedings 2014 (1): 10622. https://doi.org/10.5465/AMBPP.2014.10622symposium.

Alvarez, Sharon A., Jay B. Barney, and Philip Anderson. 2012. "Forming and Exploiting Opportunities: The Implications of Discovery and Creation Processes for Entrepreneurial and Organizational Research." Organization Science 24 (1): 301-17. https://doi.org/10.1287/orsc.1110.0727.

Amit, Raphael, and Xu Han. 2017. "Value Creation through Novel Resource Configurations in a Digitally Enabled World.” Strategic Entrepreneurship Journal 11 (3): 228-42. https://doi.org/10.1002/sej.1256.

Amit, Raphael, and Christoph Zott. 2001. "Value Creation in E-Business." Strategic Management Journal 22 (6-7): 493-520. https://doi.org/10.1002/smj.187.

Autio, Erkko, Satish Nambisan, Llewellyn D. W. Thomas, and Mike Wright. 2018. "Digital Affordances, Spatial Affordances, and the Genesis of Entrepreneurial Ecosystems." Strategic Entrepreneurship Journal 12 (1): 72-95. https://doi.org/10.1002/sej.1266.

Benkler, Yochai. 2006. The Wealth of Networks: How Social Production Transforms Markets and Freedom. New Haven, Conn.: Yale Univ. Press.

Bresnahan, Timothy, Alfonso Gambardella, and Annalee Saxenian. 2001. “'Old Economy” Inputs for 'New Economy' Outcomes: Cluster Formation in the New Silicon Valleys." Industrial and Corporate Change 10 (4): 835-60. https://doi.org/10.1093/icc/10.4.835.

Cairncross, Frances. 1997. The Death of Distance: How the Communications Revolution Will Change Our Lives. Harvard Business School Press. http://www.amazon.ca/exec/obidos/redirect?tag=citeulike0920\&path=ASIN/0875848060.

Carmody, Pádraig. 2013. "A Knowledge Economy or an Information Society in Africa? Thintegration and the Mobile Phone Revolution." Information Technology for Development 19 (1): 24-39. https://doi.org/10.1080/02681102.2012.719859.

Christensen, Clayton M., Efosa Ojomo, and Derek van Bever. 2017. “Africa's New Generation of Innovators." Harvard Business Review, no. Jan/Feb 2017 (January). https://hbr.org/2017/01/africas-new-generation-of-innovators.

Davidson, Elizabeth, and Emmanuelle Vaast. 2010. "Digital Entrepreneurship and Its Sociomaterial Enactment." In Proceedings of the 2010 43rd Hawaii International Conference on System Sciences, 1-10. HICSS '10. Washington, DC, USA: IEEE Computer Society. https://doi.org/10.1109/HICSS.2010.150.

Davidsson, Per. 2005. Researching Entrepreneurship. International Studies in Entrepreneurship 5. New York, NY: Springer.

Donner, Jonathan, and Marcela X. Escobari. 2010. "A Review of Evidence on Mobile Use by Micro and Small Enterprises in Developing Countries." Journal of International Development 22 (5): 641-658. https://doi.org/10.1002/jid.1717.

Eisenmann, Thomas. R., Geoffrey Parker, and Marshall W. Van Alstyne. 2006. "Strategies for Two-Sided Markets." Harvard Business Review 84 (10). http://www.hbs.edu/faculty/Pages/item.aspx?num=22459.

Flyvbjerg, B. 2006. "Five Misunderstandings About Case-Study Research." Qualitative Inquiry 12 (2): 219-45. https://doi.org/10.1177/1077800405284363.

Foster, Christopher, and Mark Graham. 2016. "Reconsidering the Role of the Digital in Global Production Networks." Global Networks $17 \quad$ (1): 68-88. https://doi.org/10.1111/glob.12142. 
Foster, Christopher, Mark Graham, Laura Mann, Timothy Waema, and Nicolas Friederici. 2018. "Digital Control in Value Chains: Challenges of Connectivity for East African Firms." Economic Geography $94 \quad$ (1): 68-86. https://doi.org/10.1080/00130095.2017.1350104.

Friedman, Thomas L. 2005. The World Is Flat: A Brief History of the Twenty-First Century. Macmillan.

Gao, Lucia Silva, and Bala Iyer. 2006. "Analyzing Complementarities Using Software Stacks for Software Industry Acquisitions." Journal of Management Information Systems 23 (2): 119-47. https://doi.org/10.2753/MIS0742-1222230206.

Gawer, Annabelle. 2011. Platforms, Markets and Innovation. Cheltenham: Edward Elgar.

Graham, Mark, Casper Andersen, and Laura Mann. 2015. "Geographies of Connectivity in East Africa: Trains, Telecommunications, and Technological Teleologies." Transactions of the Institute of British Geographers.

Greengard, Samuel. 2010. "Cloud Computing and Developing Nations." Communications of the ACM 53 (5): 18-20. https://doi.org/10.1145/1735223.1735232.

Henfridsson, Ola, and Bendik Bygstad. 2013. "The Generative Mechanisms of Digital Infrastructure Evolution.” Management Information Systems Quarterly 37 (3): 896931.

Huang, Jimmy, Ola Henfridsson, Martin Liu, and Sue Newell. 2017. "Growing on Steroids: Rapidly Scaling the User Base of Digital Ventures Through Digitl Innovation." Management Information Systems Quarterly 41 (1): 301-14.

Kallinikos, Jannis, Aleksi Aaltonen, and Attila Marton. 2010. "A Theory of Digital Objects." First Monday 15 (6). https://doi.org/10.5210/fm.v15i6.3033.

Katz, Michael L., and Carl Shapiro. 1985. "Network Externalities, Competition, and Compatibility." The American Economic Review 75 (3): 424-40.

Khanna, T., and K. Palepu. 1997. "Why focused strategies may be wrong for emerging markets." Harvard Business Review 75 (4): 41-48.

Kolko, Jed. 2000. "The Death of Cities? The Death of Distance? Evidence from the Geography of Commercial Internet Usage." In The Internet Upheaval: Raising Questions, Seeking Answers in Communications Policy, edited by Ingo Vogelsang and Benjamin M. Compaine, 73-98. MIT Press.

Leamer, Edward E., and Michael Storper. 2001. "The Economic Geography of the Internet Age." Journal of International Business Studies 32 (4): 641-65.

Lyytinen, Kalle, Youngjin Yoo, and Richard J. Boland Jr. 2016. "Digital Product Innovation within Four Classes of Innovation Networks.” Information Systems Journal 26 (1): 4775. https://doi.org/10.1111/isj.12093.

Malecki, Edward J. 2002. "The Economic Geography of the Internet's Infrastructure." Economic Geography $78 \quad$ (4): 399-424. https://doi.org/10.1111/j.19448287.2002.tb00193.x.

Malecki, Edward J., and Bruno Moriset. 2007. The Digital Economy: Business Organization, Production Processes and Regional Developments. London: Routledge.

Markus, M. Lynne. 1987. "Toward a 'Critical Mass' Theory of Interactive Media: Universal Access, Interdependence and Diffusion.” Communication Research 14 (5): 491-511. https://doi.org/10.1177/009365087014005003.

Miles, Matthew B., and Michael A. Huberman. 1994. Qualitative Data Analysis: An Expanded Sourcebook. 2nd ed. Vol. xiv. Thousand Oaks, CA, US: Sage Publications, Inc.

Murphy, James T., and Pádraig Carmody. 2015. Africa's Information Revolution: Technical Regimes and Production Networks in South Africa and Tanzania. Oxford, UK: John Wiley \& Sons. 
Murphy, James T., Pádraig Carmody, and Björn Surborg. 2014. "Industrial Transformation or Business as Usual? Information and Communication Technologies and Africa's Place in the Global Information Economy." Review of African Political Economy 41 (140): 264-83. https://doi.org/10.1080/03056244.2013.873024.

Nambisan, Satish. 2017. "Digital Entrepreneurship: Toward a Digital Technology Perspective of Entrepreneurship." Entrepreneurship Theory and Practice 41 (6): 1029-55. https://doi.org/10.1111/etap.12254.

Ndemo, Bitange, and Tim Weiss, eds. 2017. Digital Kenya: An Entrepreneurial Revolution in the Making. Palgrave Studies of Entrepreneurship in Africa. London: Palgrave Macmillan.

Normann, Håkon Endresen, and Jens Hanson. 2018. "The Role of Domestic Markets in International Technological Innovation Systems." Industry and Innovation 25 (5): 482 504. https://doi.org/10.1080/13662716.2017.1310651.

Ojanperä, Sanna, Mark Graham, Ralph Straumann, Stefano De Sabbata, and Matthew Zook. 2017. "Engagement in the Knowledge Economy: Regional Patterns of Content Creation with a Focus on Sub-Saharan Africa." Information Technologies \& International Development 13 (0): 33-51.

Pickren, Graham. 2018. “The Global Assemblage of Digital Flow': Critical Data Studies and the Infrastructures of Computing." Progress in Human Geography 42 (2): 225-43. https://doi.org/10.1177/0309132516673241.

Riain, Seá Ó. 2004. "The Politics of Mobility in Technology-driven Commodity Chains: Developmental Coalitions in the Irish Software Industry." International Journal of Urban and Regional Research 28 (3): 642-63. https://doi.org/10.1111/j.03091317.2004.00541.x.

Saxenian, AnnaLee. 1994. Regional Advantage: Culture and Competition in Silicon Valley and Route 128. Cambridge, MA: Harvard University Press.

Shapiro, Carl, and Hal R. Varian. 1998. Information Rules: A Strategic Guide to the Network Economy. Harvard Business Press.

Steinbock, Dan. 2003. "Globalization of Wireless Value System: From Geographic to Strategic Advantages." Telecommunications Policy $27 \quad$ (3): 207-35. https://doi.org/10.1016/S0308-5961(02)00106-4.

Strauss, Anselm, and Juliet M. Corbin. 1990. Basics of Qualitative Research: Grounded Theory Procedures and Techniques. Thousand Oaks, CA, US: Sage Publications, Inc.

Sussan, Fiona, and Zoltan J. Acs. 2017. "The Digital Entrepreneurial Ecosystem." Small Business Economics 49 (1): 55-73. https://doi.org/10.1007/s11187-017-9867-5.

Thrift, Nigel, and Shaun French. 2002. "The Automatic Production of Space." Transactions of the Institute of British Geographers 27 (3): 309-35. https://doi.org/10.1111/14755661.00057.

Tilson, David, Kalle Lyytinen, and Carsten Sørensen. 2010. "Research Commentary-Digital Infrastructures: The Missing IS Research Agenda." Information Systems Research 21 (4): 748-59. https://doi.org/10.1287/isre.1100.0318.

Trippl, Michaela, Franz Tödtling, and Lukas Lengauer. 2009. "Knowledge Sourcing Beyond Buzz and Pipelines: Evidence from the Vienna Software Sector." Economic Geography 85 (4): 443-62. https://doi.org/10.1111/j.1944-8287.2009.01047.x.

Yin, Robert K. 2009. Case Study Research: Design and Methods. 4th edition. Thousand Oaks: California Sage Publ.

Yoo, Youngjin, Richard J. Boland, Kalle Lyytinen, and Ann Majchrzak. 2012. "Organizing for Innovation in the Digitized World." Organization Science 23 (5): 1398-1408. https://doi.org/10.1287/orsc.1120.0771. 
Yoo, Youngjin, Ola Henfridsson, and Kalle Lyytinen. 2010. "Research Commentary-The New Organizing Logic of Digital Innovation: An Agenda for Information Systems Research." Information Systems Research $21 \quad$ (4): 724-35. https://doi.org/10.1287/isre.1100.0322.

Zittrain, Jonathan. 2009. The future of the Internet: and how to stop it. London: Penguin.

Zook, Matthew A. 2000. "The Web of Production: The Economic Geography of Commercial Internet Content Production in the United States." Environment and Planning A: Economy and Space 32 (3): 411-26. https://doi.org/10.1068/a32124.

2001. "Old Hierarchies or New Networks of Centrality?: The Global Geography of the Internet Content Market." American Behavioral Scientist 44 (10): 1679-96. https://doi.org/10.1177/00027640121958113.

2002. "Grounded Capital: Venture Financing and the Geography of the Internet Industry, 1994-2000.” Journal of Economic Geography 2 (2): 151-77. https://doi.org/10.1093/jeg/2.2.151.

2005. The Geography of the Internet Industry. Oxford, UK: Blackwell Publishing Ltd.

Zook, Matthew A., and Michael H. Grote. 2017. "The Microgeographies of Global Finance: High-Frequency Trading and the Construction of Information Inequality." Environment and Planning A: Economy and Space 49 (1): 121-40. https://doi.org/10.1177/0308518X16667298. 